\title{
Prognostic Significance of Glutathione S-Transferase-Pi in Invasive Breast Cancer
}

Jingxiang Huang, M.B.B.S., Puay-Hoon Tan, F.R.C.P.A., Jayabaskar Thiyagarajan. M.B.B.S., Boon-Huat Bay, Ph.D.

Department of Medical Oncology (JH), National Cancer Centre; Department of Pathology (P-HT), Singapore General Hospital; and Departments of Physiology (JB) and Anatomy (B-HB), National

University of Singapore, Singapore

Glutathione $S$-transferase pi (GST-pi), a Phase II detoxification enzyme, has recently been implicated in protection against apoptosis. Expression of GST-pi and Bcl-2 protein, an established apoptosis marker, was analyzed by immunohistochemistry in 116 cases of infiltrative ductal breast carcinomas in Singapore women. The markers were correlated with apoptosis detected by the TUNEL method and clinico-pathological parameters. There were 67 (58\%) GST-pi-positive breast tumors and 43 (37\%) Bcl-2-positive tumors. In a large proportion of GSTpi-positive/Bcl-2-positive tumors, there was a distinct accumulation of the GST-pi enzyme within the nucleus of cancer cells when examined by double immunofluorescence labeling under confocal microscopy. GST-pi immunoreactivity was not significantly correlated with any of the traditional histologic factors known to influence prognosis, whereas Bcl-2 overexpression was associated with reduced size of primary tumor $(P=.021)$ and positive estrogen receptor status $(P=.001)$. Univariate analysis revealed that GST-pi-positive, Bcl-2-positive, and lower histological grade tumors had decreased levels of apoptosis $(P=.024, P=.011$, and $P=.029$, respectively). However, multivariate analysis showed that histological grade and Bcl-2, but not GST-pi, immunoreactivity were correlated with apoptotic status. The Kaplan-Meier disease-free survival curves showed a significant difference between GST-pi-positive and GST-pi-negative breast cancer cases $(P=.002)$. Disease-free survival in patients with GST-pi-positive tumors was also worse than

Copyright () 2003 by The United States and Canadian Academy of Pathology, Inc.

VOL. 16, NO. 6, P. 558, 2003 Printed in the U.S.A

Date of acceptance: February 24, 2003.

This study was supported by a research grant from the Singapore Cancer Society and the National Medical Research Council (Grant NMRC/0612/2001)

Address reprint requests to: Boon-Huat Bay, M.B.B.S., Ph.D., Department of Anatomy, National University of Singapore, 4 Medical Drive, Blk MD10, S 117 697, Singapore; fax: 65-6778-7643; e-mail: antbaybh@nus.edu.sg.

DOI: 10.1097/01.MP.0000071842.83169.5A that in patients with GST-pi-negative tumors in the group who had adjuvant chemotherapy $(P=.04)$. In patients who were lymph node positive, GST-pi immunopositivity was found to influence disease-free survival. Recurrence of tumors was also significantly affected by GST-pi immunoreactivity (relative risk of 8.1). The findings indicate that GST-pipositive tumors are more aggressive and have a poorer prognosis than do corresponding GST-pinegative breast cancers.

KEY WORDS: Apoptosis, Bcl-2, Breast carcinoma, Confocal microscopy, Glutathione $S$-transferase, Immunohistochemistry, Survival.

Mod Pathol 2003;16(6):558-565

Glutathione $S$-transferase-pi (GST-pi) belongs to a major group of detoxification enzymes that is widely distributed in the human body (1). In normal human tissues, the enzyme protects cells against noxious compounds by catalyzing conjugating reactions with glutathione and protects against reactive oxygen species by reducing organic hydroperoxides via glutathione peroxidase activity (2). The role of GST-pi in tumor growth and progression is less well known. It is reported to be variably expressed in breast cancer (3) and is associated with estrogen receptor level expressed by the tumor $(4,5)$. Down-regulation of GST-pi activity in a T-cell line study appears to favor apoptosis (6) and inhibition of GST-pi function induces apoptosis in rat hepatoma cells (7).

The Bcl-2 protein is known to block apoptosis and prolong the life span of cells (8). It has been suggested that Bcl-2 plays a part in regulating cellular redox potential in response to oxidative stress (9). Bcl-2 is known to block lipid peroxidation and generation of reactive oxygen species and cellular redox potentials. Moreover, Bcl-2 has been reported to alter intracellular ion fluxes that occur during apoptosis, including changes in the partitioning of $\mathrm{Ca}^{2+}$ in the cellular organelles such as 
endoplasmic reticulum, nucleus, and mitochondria (10). The ability of the Bcl-2 protein to suppress apoptosis has also been linked with glutathione (11).

In the present study, the expression of GST-pi was analyzed by immunohistochemistry in breast cancer in relationship with Bcl-2 expression, apoptosis, and clinical outcome. The aim of this study was to determine the prognostic roles of GST-pi and Bcl-2 in patients with invasive ductal breast cancer. The results were correlated with clinicopathological parameters and disease-free survival.

\section{MATERIAL AND METHODS}

\section{Patients, Tumors, Pathological Evaluation, and Clinical Follow-Up}

The study population comprised 116 women diagnosed with infiltrative ductal breast carcinomas who had undergone mastectomy or lumpectomy without neoadjuvant treatment between 1998 and 1999 in the Singapore General Hospital. The tissues were fixed in $10 \%$ buffered formaldehyde ( $\mathrm{pH} 7.0)$. The age of the patients ranged from 33 to 86 years, with a median age of 52 years. There was no distant metastasis at the time of diagnosis. The tumor size, estrogen receptor status, and axillary lymph node positivity were determined. Histologic grade of the tumors was established according to the criteria described by Sloane et al. (12). Information was not available on the estrogen receptor status of two patients because they were not analyzed at the time of diagnosis. Lymph node status in two patients was unknown because they did not undergo axillary lymph node dissection. Seventy-one (61\%) patients received cytotoxic chemotherapy in addition to surgical removal of the tumors. Thirtysix $(51 \%)$ patients received the cyclophosphamide/ methotrexate/5-fluorouracil (CMF) regime, whereas the rest received adriamycin-based regimes such as adriamycin/cyclophosphamide, adriamycin/taxol, and cyclophosphamide/adriamycin/5-fluorouracil. Patient follow-up ranged from 33 to 1464 days, with a median follow-up of 1117 days. Twenty-one patients suffered recurrences, and mean disease-free interval was 981 days.

\section{Immunohistochemistry}

Paraffin-embedded sections were stained immunohistochemically for GST-pi using the polyclonal antibody anti-GST-pi antibody (Dako) at 1:200 dilution as described in detail previously (13). For Bcl-2 expression, sections were preheated in 10 $\mathrm{mmol} / \mathrm{L}$ citrate buffer at $\mathrm{pH} 6.0$ before incubation with a mouse monoclonal to human Bcl-2 (Cymbus Biotechnology) at 1:20 dilution for 90 minutes. After washing and incubation with the appropriate sec- ondary antibodies, avidin-biotin-peroxidase complex was applied for 1 hour at room temperature to amplify the specific binding of primary antibody. Visualization was achieved by incubating with $3,3^{\prime}$ diaminobenzidine tetrachloride (Sigma) as the peroxidase substrate. The sections were then counterstained with hematoxylin. GST-pi expression was considered to be positive when $>10 \%$ of tumor cells exhibited cytoplasmic or nuclear staining. Bcl-2 expression was classified as positive when $>30 \%$ of tumor cells exhibited cytoplasmic staining (14).

\section{Double Immunofluorescence Labeling}

Co-localization of GST-pi and Bcl-2 was performed on paraffin-embedded samples as previously described (15). The primary antibodies were incubated in the same medium with the tissue sections at the same concentrations as when they were used singly for immunohistochemistry. Cy3conjugated secondary anti-rabbit antibody (to detect the GST-pi antibody) at a dilution of 1:800 and FITC-conjugated secondary anti-mouse antibody (to detect the Bcl-2 antibody) at a dilution of 1:200 were then applied for 1 hour at room temperature. After washing in PBS, the sections were mounted with fluorescence mounting media (DAKO). Stained sections were viewed and photographed using the LSM 510 Carl Zeiss confocal laser scanning microscope (equipped with an argon laser) under a Plan Apo $63 \times 1.4$ NA (oil) objective. Excitation wavelength for Cy3 was at $543 \mathrm{~nm}$, and for FITC, at $488 \mathrm{~nm}$.

\section{TUNEL Method}

For the detection of apoptosis in tissue sections, DNA fragmentation was identified using the terminal deoxynucleotidyl transferase-mediated, dUTPbiotin nick end-labeling (TUNEL) technique with the commercially available TdT-FragELTM DNA Fragmentation Detection kit (Oncogene Research Products) (16) in 113 tumor sections. After deparaffinization and rehydration, slides were permeabilized in $20 \mathrm{mg} / \mathrm{mL}$ of proteinase K. Endogenous peroxidase was inactivated by treating with $3 \%$ hydrogen peroxide. Subsequently, the sections were end-labeled with biotinylated dNTP by TdT for 2 hours at $37^{\circ} \mathrm{C}$, and labeled cells were detected using streptavidin-horseradish peroxidase conjugate followed by diaminobenzidine staining. The apoptotic index was defined as the number of apoptotic nuclei per 100 cancer cell nuclei.

\section{Statistical Analysis}

For statistical analysis, SPSS software for Windows, Release 10.0, was used. Clinicopathological data was compared between groups of breast tu- 
mors with different protein expression, using either $\chi^{2}$ or Fisher's exact test. The Student's $t$ test was used to compare the mean apoptotic index for different groups of breast tumors. For multivariate analysis of factors associated with apoptosis, log transformation and multiple linear regression was used. Survival curves were plotted by the KaplanMeier method, and the differences between the curves were evaluated by log-rank test. To assess the factors influencing recurrence, multivariate analysis using Cox's proportional hazard models was performed. A $P$ value of $<.05$ was considered significant.

\section{RESULTS}

There were 67 (58\%) GST-pi-positive breast tumors with the GST-pi protein being expressed in the cytoplasm, the nucleus, or both (Fig. 1A). Fortythree $(37 \%)$ tumors were found to be bcl-2 positive (Fig. 1B). Thirty-three (28\%) tumors were both Bcl-2 and GST-pi negative, and 27 (23\%) were both Bcl-2 and GST-pi positive. Although there was no correlation between GST-pi and Bcl-2 expression $(P=$ $.441)$, Bcl-2 expression appeared to affect the local- ization of GST-pi. In a large proportion of GST-pipositive/Bcl-2-positive tumors examined, there was a distinct accumulation of the GST-pi enzyme within the nuclei of cancer cells in addition to the cytoplasmic staining when observed by double immunofluorescence labeling under confocal microscopy (Fig. 1, C-E). Localization of Bcl-2 in the cytoplasm is represented by green fluorescence, and GST-pi expression in the cytoplasm/nucleus, by red fluorescence, whereas co-localization of cytoplasmic GST-pi with Bcl-2 is shown by orange fluorescence.

Table 1 shows the distribution of patients according to clinical and histopathological variables. The proportion of GST-pi-positive tumors was not significantly correlated with any of the histologic factors traditionally used for prognosis. In contrast, Bcl-2 overexpression was associated with reduced size of primary tumor $(P=.021)$ and positive estrogen receptor status $(P=.001)$.

Interestingly, GST-pi-positive tumors and Bcl-2positive tumors had significantly lower apoptotic indices compared with the case of their negative counterparts (Table 2). Histological Grade I and II tumors also had lower apoptotic indices as com-
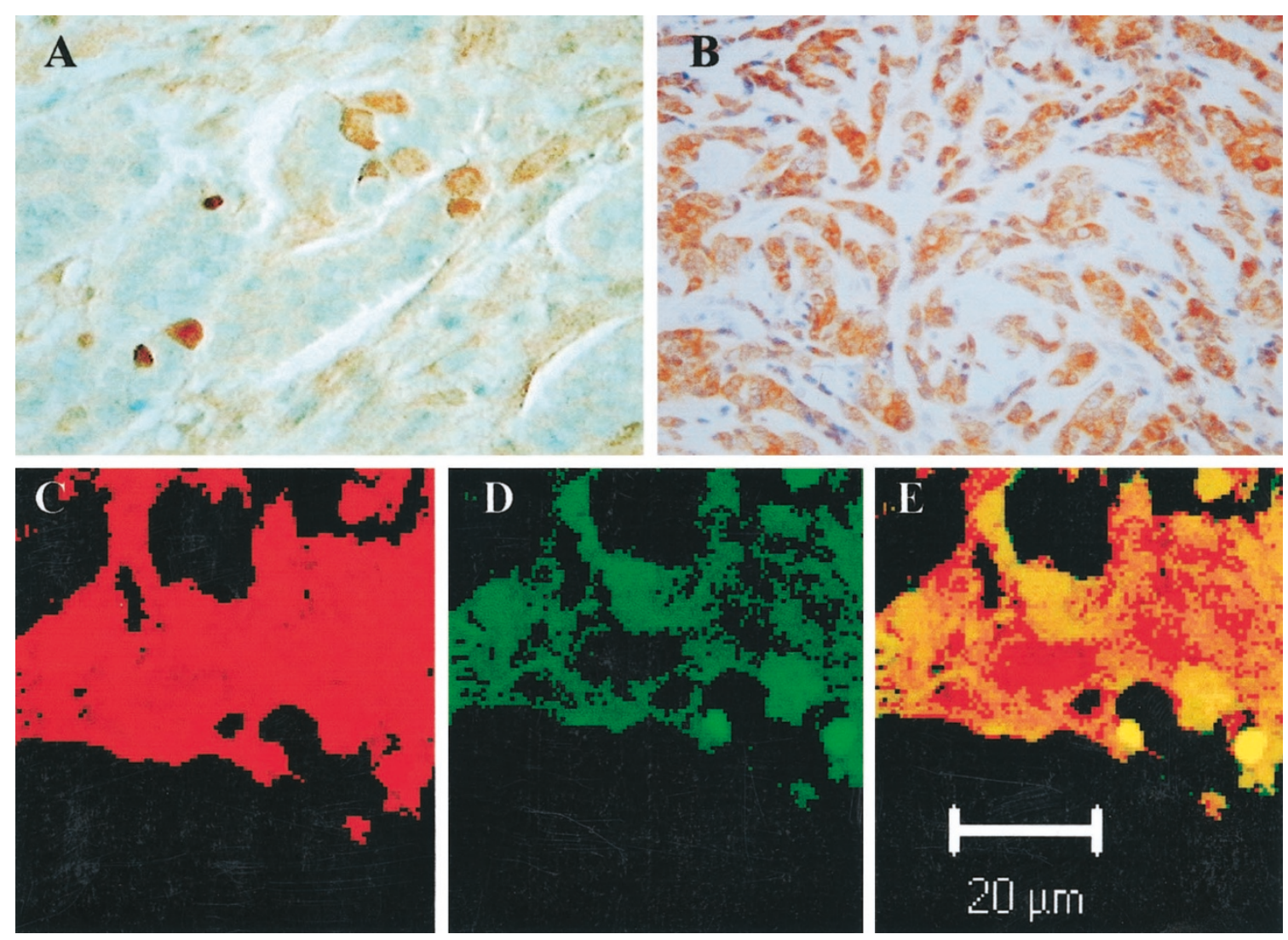

FIGURE 1. Composite figures of immunohistochemical stains of GST-pi (A) and Bcl-2 (B) and double immunofluorescence staining of GST-pi (CE). A, cytoplasmic staining of GST-pi protein in a few breast cancer cells. Immunoperoxidase stain; original magnification, 200 $\times$. B, Bcl-2-positive immunoreactivity in breast cancer showing cytoplasmic staining. Immunoperoxidase stain; original magnification, $400 \times$. C, breast cancer cells staining positively with red fluorescence for GST-pi immunoreactivity. D, breast cancer cells staining positively with green fluorescence for bcl-2 immunoreactivity. E, co-localization of GST-pi and bcl-2 in the cytoplasm of the breast cancer cells (orange fluorescence). Nuclear localization of GST-pi is indicated by the red fluorescence. $(\mathbf{C}, \mathbf{D}$, and $\mathbf{E}$, bar $=20 \mu \mathrm{m})$. 
TABLE 1. Relation between Over-Expression of GST-pi and Bcl-2 with Clinico-Pathological Factors

\begin{tabular}{|c|c|c|c|}
\hline $\begin{array}{c}\text { Clinico-Pathological } \\
\text { Factors }\end{array}$ & $\begin{array}{c}\text { Number of } \\
\text { Patients }\end{array}$ & $\begin{array}{c}\text { GST } \\
\text { pi-Positive }\end{array}$ & Bcl2-Positive \\
\hline \multicolumn{4}{|l|}{ Patient age } \\
\hline 50 years and below & 50 & 31 & 23 \\
\hline More than 50 years & 66 & 36 & 20 \\
\hline$P$ & & .453 & .120 \\
\hline \multicolumn{4}{|l|}{ Primary tumor } \\
\hline $\mathrm{T} 1$ & 21 & 12 & 13 \\
\hline $\mathrm{T} 2$ & 82 & 47 & 26 \\
\hline $\mathrm{T} 3$ and $\mathrm{T} 4$ & 13 & 8 & 3 \\
\hline$P$ & & .613 & .021 \\
\hline \multicolumn{4}{|l|}{ Regional Lymph nodes } \\
\hline Positive & 63 & 35 & 21 \\
\hline Negative & 51 & 30 & 21 \\
\hline$P$ & & 1.000 & .560 \\
\hline \multicolumn{4}{|l|}{ Estrogen receptor } \\
\hline Positive & 74 & 44 & 35 \\
\hline Negative & 40 & 23 & 6 \\
\hline$P$ & & .845 & .001 \\
\hline \multicolumn{4}{|l|}{ Histologic grade } \\
\hline I & 11 & 7 & 6 \\
\hline II & 43 & 24 & 16 \\
\hline III & 62 & 36 & 21 \\
\hline$P$ & & .894 & .425 \\
\hline
\end{tabular}

TABLE 2. Mean Apoptotic Index in Relation to ClinicoPathological Factors

\begin{tabular}{lc}
\hline \multicolumn{1}{c}{ Clinico-Pathological } & $\begin{array}{c}\text { Apoptotic Index } \\
\text { (Mean } \pm \text { SEM) }\end{array}$ \\
\hline Patient age & $1.22 \pm 0.22$ \\
50 years and below & $1.40 \pm 0.20$ \\
More than 50 years & .547 \\
$P$ & \\
Primary tumor & $0.94 \pm 0.29$ \\
T1 & $1.40 \pm 0.17$ \\
T2, T3 and T4 & .236 \\
$P$ & $1.42 \pm 0.22$ \\
Regional lymph nodes & $1.21 \pm 0.20$ \\
Positive & .439 \\
Negative & \\
$P$ & $1.27 \pm 0.21$ \\
Estrogen receptor & $1.49 \pm 0.20$ \\
Positive & .486 \\
Negative & \\
$P$ & $0.97 \pm 0.17$ \\
Histologic grade & $1.62 \pm 0.23$ \\
I and II & .029 \\
III & \\
$P$ & $1.05 \pm 0.14$ \\
GST-pi expression & $1.72 \pm 0.30$ \\
Positive & .024 \\
Negative & \\
$P$ & $0.82 \pm 0.12$ \\
Bcl-2 expression & $1.60 \pm 0.22$ \\
Positive & .011 \\
Negative & \\
$P$ & \\
\hline & \\
\hline &
\end{tabular}

pared with the case of the Grade III tumors. There was no correlation of the apoptotic index with tumor size, axillary lymph node positivity, or estrogen receptor status. However, when analyzed by multivariate analysis, only histological grade and $\mathrm{Bcl}-2$ immunoreactivity were found to be correlated with apoptosis ( $P=.008$ and $P=.015$, respectively), whereas there was no association between GST-pi immunoreactivity and apoptosis $(P=.177)$.
The Kaplan-Meier survival curves revealed a significant difference between GST-pi-positive and GST-pi-negative cases $(P=.002$; Fig. 2$)$ but not between Bcl-2-positive and Bcl-2 negative ones $(P$ $=.08$; Fig. 3 ). The time to recurrence was also significantly affected by GST-pi immunoreactivity ( $P=.007)$, with GST-pi immunopositive tumors having a shorter recurrence-free interval, whereas there was no association with Bcl-2 immunoreactivity $(P=.09)$. Surgically treated breast cancer patients who received adjuvant chemotherapy and are categorized by GST-pi and Bcl-2 status are shown in Table 3. Although there was no significant difference in disease-free survival between Bcl-2 status and the treatment regime after surgery $(P=$ .14 and $P=.21$ for surgery alone and surgery with adjuvant chemotherapy respectively), GST-pi-positive cases had significantly poorer survival in both groups of patients (Fig. 4 and Fig. 5).

Even though the mean number of positive axillary lymph nodes in GST-pi-positive and GST-pinegative cases was not significantly different $(4.0 \pm$ 0.7 versus $6.0 \pm 1.1$ respectively; $P=.134$ ), GST-pi immunoreactivity was observed to influence disease-free survival in lymph node-positive cases. $(P=.002$; Fig. 6$)$. Details of this subset of patients with respect to other clinicopathologic parameters are shown in Table 4.

When factors influencing recurrence were analyzed by multivariate analysis, GST-pi status was found to significantly influence disease-free survival $(P=.006)$, with $\mathrm{Bcl}-2$ status having a marginal influence over disease-free survival $(P=.067$; Table $5)$. The risk of tumor recurrence was eight times higher in patients with GST-pi-positive breast tumors, as the relative risk was 8.1. Conversely, Bcl-2 expression reduced the risk of recurrence in breast cancer patients (relative risk of .31).

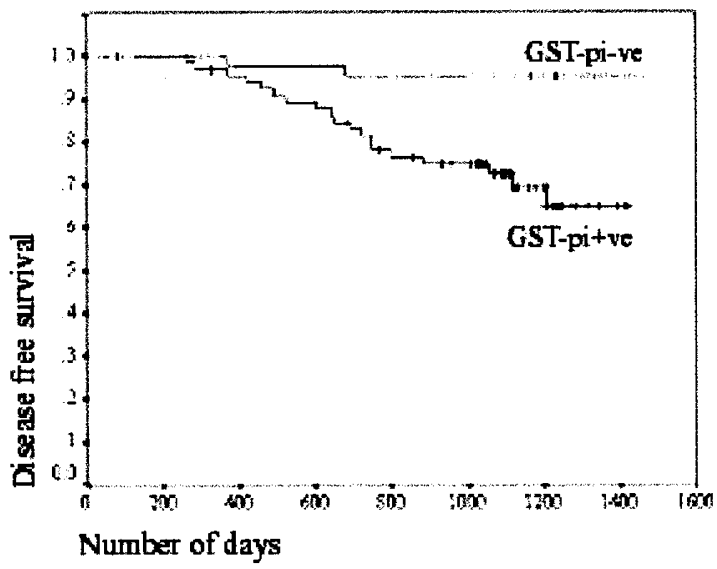

FIGURE 2. Disease-free survival in patients with GST-pi-positive tumors was worse than that of patients with GST-pi-negative tumors $(P$ $=.002)$. 


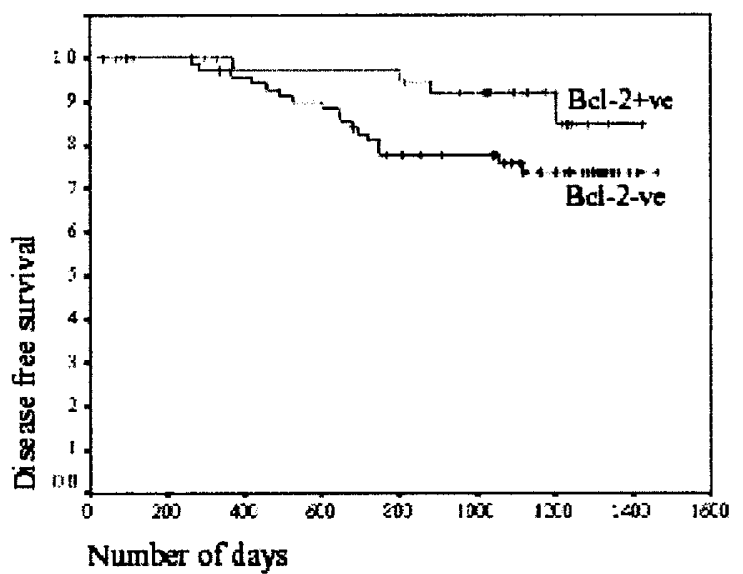

FIGURE 3. Disease-free survival in patients was not affected by Bcl-2 status $(P=.08)$.

TABLE 3. Treatment Regime of Breast Cancer Patients after Surgery as Stratified By Bcl-2 and GST-pi Status

\begin{tabular}{lcc}
\hline \multicolumn{1}{c}{$\begin{array}{c}\text { Biomarker } \\
\text { Status }\end{array}$} & $\begin{array}{c}\text { No } \\
\text { Chemotherapy }\end{array}$ & $\begin{array}{c}\text { With Adjuvant } \\
\text { Chemotherapy }\end{array}$ \\
\hline GST-pi positive & 27 & $40(22$ on CMF $)$ \\
GST-pi negative & 18 & $31(14$ on CMF $)$ \\
Bcl-2 positive & 19 & $24(12$ on CMF $)$ \\
Bcl-2 negative & 26 & $47(24$ on CMF $)$ \\
\hline
\end{tabular}

$\mathrm{CMF}=$ cyclophosphamide/methotrexate/5-fluorouracil regime.

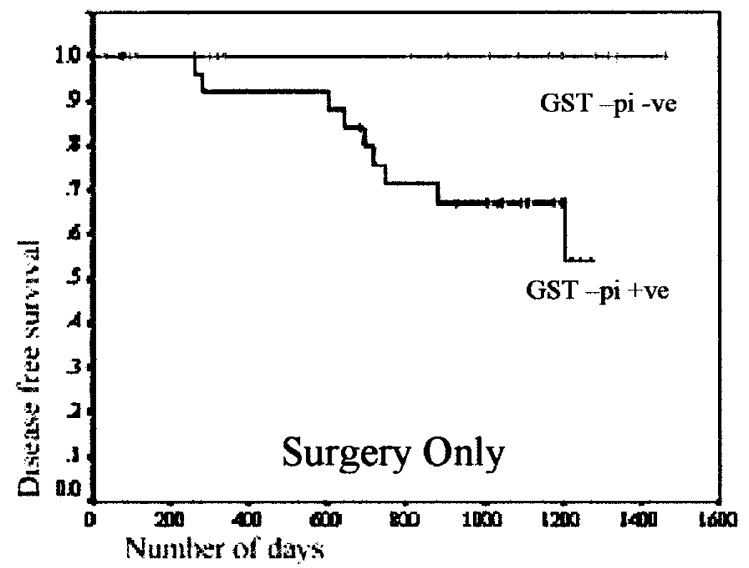

FIGURE 4. Disease-free survival in patients with GST-pi-positive tumors was inferior to that in patients with GST-pi-negative tumors who underwent surgery without chemotherapy $(P=.02)$.

\section{DISCUSSION}

In the present study, GST-pi overexpression was detected in $58 \%$ of the breast cancer tissues examined. This finding is similar to that reported in Caucasian populations $(17,18)$. We observed that GST-pi expression was not associated with estrogen receptor status with a larger sample, although in a previous smaller study, we found that GST-pi expression was associated with estrogen receptor negativity (13). This may be due to subtle differences in tumor characteristics between the two

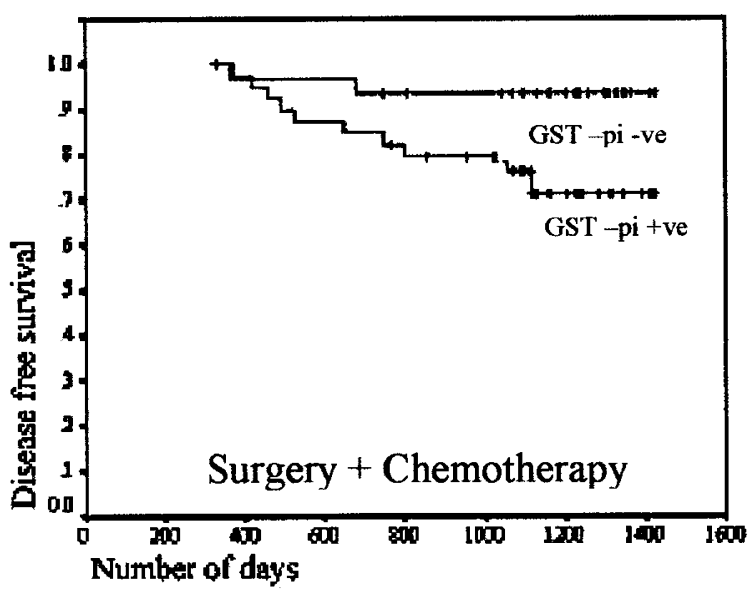

FIGURE 5. Disease-free survival in patients with GST-pi-positive tumors was worse than that of patients with GST-pi-negative tumors in the group who had adjuvant chemotherapy $(P=.04)$.

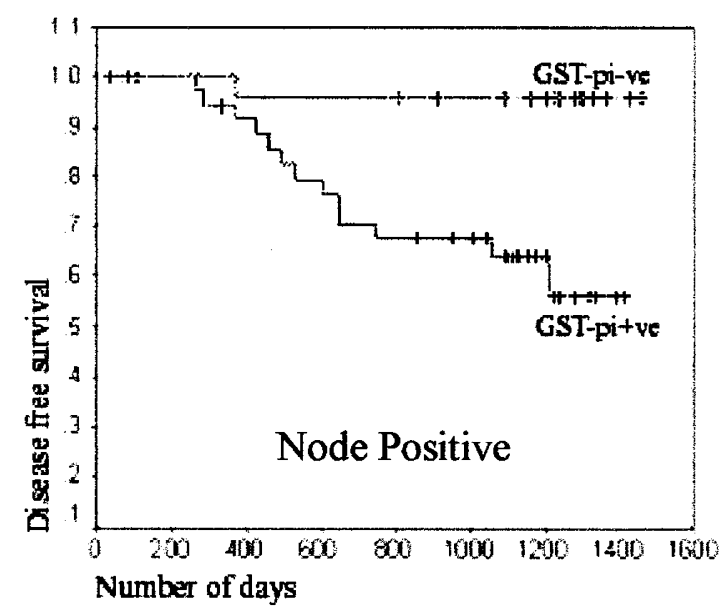

FIGURE 6. Disease-free survival in node-positive patients was significantly correlated with GST-pi immunoreactivity $(P=.002)$.

TABLE 4. Relation of GST-pi Expression with ClinicoPathological Factors in Axillary Lymph Node Positive Cases

\begin{tabular}{lcccc}
\hline $\begin{array}{c}\text { Clinico-Pathological } \\
\text { Factors }\end{array}$ & $\begin{array}{c}\text { Number of } \\
\text { Patients }\end{array}$ & $\begin{array}{c}\text { GST pi- } \\
\text { Positive }\end{array}$ & $\begin{array}{c}\text { GST pi- } \\
\text { Negative }\end{array}$ & P Value \\
\hline Primary tumor & & & & .652 \\
T1 & 9 & 5 & 4 & \\
T2 & 42 & 17 & 25 & \\
T3 and T4 & 12 & 5 & 7 & .434 \\
Estrogen receptor & & & & \\
$\quad$ Positive & 39 & 18 & 21 & \\
$\quad$ Negative & 23 & 8 & 15 & .285 \\
Histologic grade & & & & \\
I & 8 & 2 & 6 & \\
II & 24 & 13 & 11 & \\
III & 31 & 12 & 19 & \\
\hline
\end{tabular}

samples, as differences in patient selection could result in the presence or absence of this association.

Only $37 \%$ of the breast cancers exhibited Bcl-2 overexpression, compared with $49 \%$ (19) and $63 \%$ (20) in two studies that used the same cutoff to define Bcl-2 overexpression. Whether such varia- 
TABLE 5. Cox's Multivariate Analysis of Disease Free Survival in Breast Cancer Patients

\begin{tabular}{ll}
\hline Clinico-Pathological Factors & $P$ Value \\
\hline Lymph node status & .307 \\
Estrogen receptor status & .374 \\
Bcl-2 status & .067 \\
GST-pi status & .006 \\
Tumor stage & .971 \\
\hline
\end{tabular}

tions were due to population differences await further confirmatory studies. Nevertheless, consistent with those studies, a higher proportion of Bcl-2overexpressing tumors remains associated with estrogen receptor-positive tumors and tumors with better prognostic characteristics such as smaller size.

GST-pi immunoreactivity was observed to be diffusely located in the cytoplasm in most of the Bcl2-negative tumors. In contrast, there appeared to be an increased nuclear localization of the GST-pi protein in Bcl-2-overexpressing tumors, as clearly demonstrated by two-color immunofluorescence with confocal microscopy. One plausible explanation for this observed phenomenon is that the Bcl-2 protein has been implicated as a regulator of transport through the nuclear pore (21). GST-pi, which has a molecular weight of $22 \mathrm{kDa}$, has the potential to gain entry into the nucleus through the nuclear pore complex (22). The precise role of GST-pi in the nucleus has not been ascertained, although an increased amount of nuclear GST-pi expression has been observed in breast cancer cells resistant to doxorubicin and cis-diamminedichloroplatinum (II; 23). The findings of that study showed that GST-pi was transferred to the nucleus when cells were exposed to the anticancer drugs, thus preventing DNA damage by inhibiting DNA intercalation and DNA cross-linking.

Apoptosis is a fundamental biological process that plays an important role in carcinogenesis (24). It is well established that this process could be triggered by a variety of agents, including oxidants (25). Oxidative damage to cells is known to be blocked by antioxidants, which have the capacity to scavenge reactive oxygen species (26). GST-pi is an antioxidant that is known to inhibit c-Jun $N$-terminal kinases that are required for maximal induction of apoptosis by DNA damaging agents, a pathway which is mediated by Bcl-2 (27). In addition, the GST family of enzymes has the capacity to prevent oxidative damage by catalyzing conjugation of electrophiles (28). However, we did not find a significant correlation of GST-pi expression with apoptosis when evaluated by multivariate analysis.

On the other hand, a higher Bcl-2 immunoreactivity was associated with a lower extent of apoptosis, a finding which is similar to that reported by Vakkala et al. (29). Suppression of apoptosis is re- ported to increase mutation frequency (30), and loss of apoptosis is associated with accumulation of oncogenes (31). By delaying cell death, the Bcl-2 protein may help to promote the accumulation of mutations, allowing cancer cells to acquire a more malignant phenotype. In view of its anti-apoptotic effects, Bcl-2 expression would apparently promote tumorigenesis. However, Bcl-2 is generally accepted as a favorable prognostic marker in breast carcinoma (32). In our study, Bcl-2-positive cases appeared to have improved disease-free survival (though not statistically significant). This is understandable, as prognosis is influenced by a host of other factors besides apoptosis. Although dysregulation of apoptosis is known to play an important role in metastasis (33), yet we observed no correlation of lymph node metastasis with Bcl-2.

It has also been demonstrated that the more aggressive infiltrative ductal carcinoma has a lower degree of apoptosis and higher proliferative activity compared with the case of intraductal carcinoma (34). This contrasts with our finding, in which a higher histological grade was observed to be associated with a raised apoptotic index. In his review, Lipponen (35) stated that increased apoptotic values in breast cancer are related to high histological grade and that the apoptotic index shows a positive correlation with indicators of cell proliferation such as mitotic index. Mitotic activity is one of the factors used in determining histological grade (12), and this could explain why histological Grade III tumors had higher apoptotic values than Grade I and II breast tumors.

The GST family of enzymes has long been implicated in chemotherapeutic drug resistance (36). Chemoresistance is a major cause for failure in cancer therapy, and modulation of cellular proteins such as GST-pi involved in detoxification has been suggested as one of the mechanisms that contribute to drug resistance (37). GST-pi expression has been reported to be related to clinical drug resistance (38). In our study, we found a significantly poorer disease-free survival in patients with GSTpi-positive breast tumors who received adjuvant chemotherapy after surgery, as compared with patients who had GST-pi-negative tumors.

Earlier on, Gilbert et al. (5) suggested that increased GST-pi expression could be an important predictor of early recurrence and death in nodenegative breast cancer patients. We observed that patients with GST-pi immunopositivity had a higher relative risk of recurrence (8 times) when compared with their GST-pi-negative counterparts. This finding is in accord with that reported by Silverstrini and co-workers (18), who found that the risk of local recurrence at 6 years was higher for patients with tumors exhibiting elevated levels of GST-pi protein. On the other hand, our finding of a 
reduced risk of recurrence in breast cancer patients with Bcl-2 expression (although the $P$ value was marginally significant) is in concert with that reported by Castiglione and colleagues (39). They observed that a positive Bcl-2 status had a favorable impact on recurrence-free survival in European patients with breast cancer.

In conclusion, GST-pi expression appears to be an independent predictor of poor prognosis in breast cancer patients. Disease-free survival was worse in patients with GST-pi-positive breast tumors, and the relative risk of tumor recurrence was higher. GST-pi was linked with unfavorable disease outcome in node-positive breast cancer patients. It would appear that GST-pi can be added to the list of new and promising prognostic factors, such as tumor angiogenesis, epidermal growth factor receptor, and transforming growth factor alpha, that provide significant information in the clinical management of breast cancer patients (40).

Acknowledgments: We thank Dr. Dong Fang and Mr. Chun-Peng Low for assistance.

\section{REFERENCES}

1. Terrier P, Townsend AJ, Coindre JM, Triche TJ, Cowan KH. An immunohistochemical study of pi class glutathione $S$-transferase expression in normal tissue. Am J Pathol 1990; 137:845-53.

2. Batist G, Tulpule A, Sinh BK, Katki AG, Myers CE, Cowan KH. Over-expression of a novel anionic glutathione transferase in multi-drug resistant human breast cancer cells. J Biol Chem 1986;261:15544-9.

3. Perquin M, Oster T, Maul A, Froment N, Untereiner M, Bagrel D. The glutathione-related detoxification pathway in the human breast: a highly coordinated system disrupted in the tumour tissues. Cancer Lett 2000;158:7-16.

4. Howie AF, Miller WR, Hawkins RA, Hutchinson AR, Beckett GJ. Expression of glutathione $S$-transferase B1, B2, Mu and Pi in breast cancers and their relationship to estrogen receptor status. Br J Cancer 1989;60:834-7.

5. Gilbert L, Elwood LJ, Merno M, Masood S, Barnes R, Steinberg SM, et al. A pilot study of pi-class glutathione-Stransferase expression in breast cancer: correlation with oestrogen receptor expression and prognosis in node-negative breast cancer. J Clin Oncol 1993;11:49-58.

6. Bernardini S, Bernassola F, Cortese C, Ballerini S, Melino G, Motti C, et al. Modulation of glutathione S-transferase P1-1 activity by polymerization during apoptosis. J Cell Biochem 2000;77:645-53.

7. Asakura T, Hashizume Y, Tashiro K, Searashi Y, Ohkawa K, Nishihira J, et al. Suppression of GST-P by treatment with glutathione-doxorubicin conjugate induces potent apoptosis in rat hepatoma cells. Int J Cancer 2001;94:171-7.

8. Korsmeyer SJ. Bcl-2 initiates a new category of oncogenes: regulators of cell death. Blood 1992;80:879-86.

9. Hockenbery DM, Oltvai ZN, Yin XM, Milliman CL, Korsmeyer SJ. Bcl-2 functions in an antioxidant pathway to prevent apoptosis. Cell 1993;75:241-51.

10. Marin MC, Fernandez A, Bick RJ, Brisbay S, Buja LM, Snuggs $\mathrm{M}$, et al. Apoptosis suppression by bcl-2 is correlated with the regulation of nuclear and cytosolic $\mathrm{Ca}^{2+}$. Oncogene 1996;12:2259-66.
11. Armstrong JS, Jones DP. Glutathione depletion enforces the mitochondrial permeability transition and causes cell death in Bcl-2 overexpressing HL60 cells. FASEB J 2002;16:1263-5.

12. Sloane JP, Anderson TJ, Blamey RW, Brown CL, Chamberlain J, Coyne J, et al. Pathology reporting in breast cancer screening. 2nd ed. National coordinating group for breast screening pathology. NHSBSP Publication No. 3, 1995; p. 19-21.

13. Huang J, Bay BH, Tan PH. Nuclear morphometry and glutathione $S$-transferase pi expression in breast cancer. Oncol Rep 2000;7:609-13.

14. Silvestrini R, Veneroni S, Daidone MG, Benini E, Boracchi P, Mezzetti M, et al. The Bcl-2 protein: a prognostic indicator strongly related to p53 in lymph node-negative breast cancer patients. J Natl Cancer Inst 1994;86:499-504.

15. Jin R, Chow VTK, Tan PH, Dheen ST, Duan W, Bay BH. Metallothionein 2A expression is associated with cell proliferation. Carcinogenesis 2002;23:81-6.

16. Jayasurya A, Bay BH, Yap WM, Tan NG. Correlation of metallothionein expression with apoptosis in nasopharyngeal carcinoma. Br J Cancer 2000;82:1198-203.

17. Murray GI, Weaver RJ, Paterson PJ, Ewen SWB, Melvin WT, Burke MD. Expression of xenobiotic metabolizing enzymes in breast cancer. J Pathol 1993;169:347-53.

18. Silverstrini R, Veronesi U, Zucali R, Kenda R, Maucione A, Leutner M. Expression of p53, glutathione $S$-transferase-pi, and $\mathrm{Bcl}-2$ proteins and benefit from adjuvant radiotherapy in breast cancer. J Natl Cancer Inst 1997;89:605-7.

19. Sierra A, Castellsague X, Coll T, Manas S, Escobedo A, Moreno A, et al. Expression of death-related genes and their relationship to loss of apoptosis in T1 ductal breast carcinomas. Int J Cancer (Pred Oncol) 1998;79:103-10.

20. Le MG, Mathieu MC, Douc-Rasy S, Le Bihan ML, Adb El All $\mathrm{H}$, Spielmann M, et al. C-myc, p53 and bcl-2, apoptosisrelated genes in infiltrating breast carcinomas: evidence of a link between bcl-2 protein over-expression and a lower risk of metastasis and death in operable patients. Int J Cancer (Pred Oncol) 1999;84:562-7.

21. Herrmann JL, Bruckheimer E, McDonnel TJ. Cell death signal transduction and Bcl-2 function. Biochem Soc Trans 1996;24:1059-65.

22. Jayasurya A, Yap WM, Tan NG, Tan BKH, Bay BH. Glutathione $S$-transferase $\pi$ expression in nasopharyngeal cancer. Arch Otolaryngol Head Neck Surg 2002;128:1396-9.

23. Goto S, Ihara Y, Urata Y, Izumi S, Abe K, Koji T, et al. Doxorubicin-induced DNA. intercalation and scavenging by nuclear glutathione $S$-transferase pi. FASEB J 2001;15:270214.

24. Metcalfe A, Streuli C. Epithelial apoptosis. Bioessays 1997; 19:711-20.

25. Eneman JD, Potts RJ, Osier M, Shukla GS, Lee CH, Chiu JF, et al. Suppressed oxidant-induced apoptosis in cadmium adapted alveolar epithelial cells and its potential involvement in cadmium carcinogenesis. Toxicology 2000;147:21528.

26. Briehl MM, Baker A. Modulation of the antioxidant defence as a factor in apoptosis. Cell Death Differ 1996;3:63-70.

27. Wang $\mathrm{T}$, Arifoglu $\mathrm{P}$, Ronai $\mathrm{Z}$, Tew KD. Glutathione $S$-transferase PI-1 inhibits c-Jun $N$-terminal kinase (JNK1) signaling through interaction with the C-terminus. J Biol Chem 2001;276:20999-1003.

28. Strange RC, Spiteri M, Sudarshan R, Fryer A. Glutathione-Stransferase family of enzymes. Mutat Res 2001;482:21-6.

29. Vakkala M, Lahteenmaki K, Raunio H, Paakko P, Soini Y. Apoptosis during breast carcinoma progression. Clin Cancer Res 1999;5:319-24.

30. Sierra A, Castellsague X, Escobedo A, Lloveras B, GarciaRamirez M, Moreno A, et al. Bcl-2 with loss of apoptosis allows accumulation of genetic alterations: a pathway to 
metastatic progression in human breast cancer. Int J Cancer (Pred Oncol) 2000;89:142-7.

31. Cherbonnel-Lasserre C, Gauny S, Kronenberg A. Suppression of apoptosis by Bcl-2 or Bcl-XL promotes susceptibility to mutagenesis. Oncogene 1996;13:1489-97.

32. Fitzgibbons PL, Page DL, Weaver D, Thor A, Allred DG, Clark $\mathrm{GM}$, et al. Prognostic factors in breast cancer. College of American Pathologists Consensus Statement 1999. Arch Pathol Lab Med 2000:124:966-78.

33. Shin MS, Kim HS, Lee SH, Park WS, Kim SY, Park JY, et al. Mutations of tumor necrosis factor-related apoptosis inducing ligand receptor 1 (TRAIL-R1) and receptor 2 (TRAIL-R2) genes in metastatic breast cancers. Cancer Res 2001;61:4942-6.

34. Shen K-L, Harn H-J, Ho L-I, Yu C-P, Chui S-C, Lee W-H. The extent of proliferative and apoptotic activity in intraductal and invasive ductal breast carcinomas detected by Ki-67 labeling and terminal deoxynucleotidyl transferasemediated digoxigenin-11-dUTP nick end labeling. Cancer 1998;82:2373-81.
35. Lipponen P. Apoptosis in breast cancer: relationship with other pathological parameters. Endocr Relat Cancer 1999;6: $13-6$.

36. Shen H, Kauvar L, Tew KD. Importance of glutathione and associated enzymes in drug response. Oncol Res 1997;9:295302.

37. el-Deiry WS. Role of oncogenes in resistance and killing by cancer therapeutic agents. Curr Opin Oncol 1997;9:79-87.

38. Nakanishi Y, Kawasaki M, Bai F, Takayama K, Pei XH, Takano $\mathrm{K}$, et al. Expression of p53 and glutathione $S$-transferase-pi relates to clinical drug resistance in nonsmall cell lung cancer. Oncology 1999;57:318-23.

39. Castiglione F, Sarotto I, Fontana V, Destefanis M, Venturio A, Ferro S, et al. Bcl2, p53 and clinical outcome in a series of 138 operable breast cancer patients. Anticancer Res 1999;19: 4555-63.

40. Fitzgibbons PL. Breast cancer. In: Gospodarowicz MK, Henson DE, Hutter RVP, O'Sullivan B, Sobin LH, Wittekind Ch, editors. Prognostic factors in cancer. New York: Wiley-Liss; 2001. p. $467-87$. 